\title{
A statistical comparison of SuperDARN spectral width boundaries and DMSP particle precipitation boundaries in the afternoon sector ionosphere
}

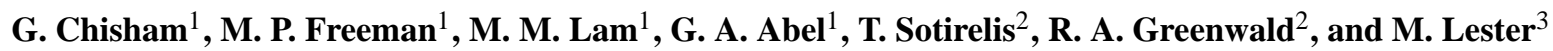 \\ ${ }^{1}$ British Antarctic Survey, Natural Environment Research Council, High Cross, Madingley Road, Cambridge, CB3 0ET, UK \\ ${ }^{2}$ Applied Physics Laboratory, Johns Hopkins University, 11100 Johns Hopkins Road, Laurel, MD 20723, USA \\ ${ }^{3}$ Radio and Space Plasma Physics Group, University of Leicester, Leicester, LE1 7RH, UK
}

Received: 15 July 2005 - Revised: 10 November 2005 - Accepted: 21 November 2005 - Published: 23 December 2005

\begin{abstract}
The open-closed magnetic field line boundary $(\mathrm{OCB})$ is best measured at the foot points of the boundary in the Earth's ionosphere where continuous and extensive spatiotemporal measurements can be made. The ability to make routine observations of this type is crucial if accurate global measurements of energy transfer processes occurring at the boundary, such as magnetic reconnection, are to become a reality. The spectral width boundary (SWB) measured by the Super Dual Auroral Radar Network (SuperDARN) has been shown to be a reliable ionospheric proxy for the OCB at certain magnetic local times (MLTs). However, the reliability of the SWB proxy in the afternoon sector ionosphere (12:00-18:00 MLT) has been questionable. In this paper we undertake a statistical comparison of the latitudinal locations of SWBs measured by SuperDARN and particle precipitation boundaries (PPBs) measured by the Defense Meteorological Satellite Program (DMSP) spacecraft, concentrating on the PPB which best approximates the location of the OCB. The latitudes of SWBs and PPBs were identified using automated algorithms applied to 5 years (1997-2001) of data measured in the 12:00-18:00 MLT range. A latitudinal difference was measured between each PPB and the nearest SWB within $\mathrm{a} \pm 10$ min universal time (UT) window and within $\mathrm{a} \pm 1 \mathrm{~h}$ MLT window. The results show that when the SWB is identified at higher geomagnetic latitudes (poleward of $\sim 74^{\circ}$ ), it is a good proxy for the OCB, with $76 \%$ of SWBs lying within $3^{\circ}$ of the OCB. At lower geomagnetic latitudes (equatorward of $\sim 74^{\circ}$ ), the correlation is poor and the results suggest that most of the SWBs being identified represent ionospheric variations unassociated with the OCB, with only $32 \%$ of SWBs lying within $3^{\circ}$ of the OCB. We propose that the low level of precipitating electron energy flux, typical of latitudes well equatorward of the OCB in the afternoon sector, may be a factor in enhancing spectral width values at these lower latitudes. A consequence of this would be low latitude SWBs unrelated to the OCB.
\end{abstract}

\footnotetext{
Correspondence to: G. Chisham

g.chisham@bas.ac.uk
}

Keywords. Ionosphere (Plasma convection; Instruments and techniques) - Magnetospheric physics (Magnetopause, cusp and boundary layers)

\section{Introduction}

Understanding the processes which control the transfer of mass, momentum and energy from the solar wind into the Earth's magnetosphere is a major goal in magnetospheric science. Most of this energy transfer occurs through the process of magnetic reconnection, in which geomagnetic flux is transferred between closed field line regions (with both ends connected to the Earth's ionosphere), and open field line regions (with one end connected to the interplanetary magnetic field (IMF)). By identifying and tracking the open-closed field line boundary (OCB), the addition and removal of open magnetic flux can be measured, and hence, the net global reconnection rate can be determined (Siscoe and Huang, 1985; Cowley and Lockwood, 1992; Milan et al., 2003, 2004). In combination with $\boldsymbol{E} \times \boldsymbol{B}$ velocity measurements at the boundary, the temporal and spatial structure of the magnetic reconnection rate can be determined (Baker et al., 1997; Pinnock et al., 2003) and contributions from magnetopause and magnetotail reconnection can be separated (Milan et al., 2003). The location of the OCB is best measured in the ionosphere where continuous and extensive spatiotemporal measurements of the boundary can be made.

Determining reliable proxies for the ionospheric signature of the OCB is thus crucial for making accurate ionospheric measurements of reconnection. A number of proxies for the OCB have been identified in a wide range of ionospheric observational data, and they vary in their usefulness and accuracy. One proxy, which has the potential to provide global measurements of the OCB at high spatiotemporal resolution, is the spectral width boundary (SWB) measured by HF radars which comprise the Super Dual Auroral Radar Network (SuperDARN). SuperDARN presently comprises 9 Northern Hemisphere, and 7 Southern Hemisphere, HF radars whose 
fields of view cover much of the polar ionospheres (Greenwald et al., 1995). The width of Doppler spectra measured by the radars has proved a good diagnostic for different regions of the ionosphere (Baker et al., 1995; André et al., 2002; Villain et al., 2002). This spectral width has been shown to be typically high in regions immediately poleward of the OCB and low in regions immediately equatorward, and far poleward, of the OCB (Villain et al., 2002). The latitudinal transition from low to high spectral width is termed the spectral width boundary.

Recent studies have systematically compared the locations of SWBs with particle precipitation boundaries (PPBs) measured by the Defense Meteorological Satellite Program (DMSP) spacecraft across a wide range of magnetic local times (MLTs). These comparisons have led to a better evaluation of the SWB as a proxy for the OCB in different MLT sectors. Specifically, the SWB is a good proxy for the OCB in the pre-midnight sector (18:00-02:00 MLT) and noon sector (08:00-12:00 MLT) but is located $\sim 2^{\circ}-4^{\circ}$ equatorward of the OCB across much of the morning sector (02:0008:00 MLT) (Chisham et al., 2004, 2005a). This observation, combined with the observations of Carbary et al. (2003), led Chisham et al. (2005a) to suggest that the spectral width observed by the SuperDARN radars is inversely correlated with the energy flux of precipitating electrons. This inferred correlation has helped to address the outstanding question of the source of enhancements in spectral width in SuperDARN data. We suggest two possible models: One is that high spectral width is caused by velocity structure on scales less than the radar range gate which is suppressed by high Pedersen conductivity caused by high electron energy flux (Parkinson et al., 2004). Alternatively, low spectral width is due to irregularities with long lifetimes (Moorcroft, 2004) which are prolonged due to high electron energy fluxes.

In the early afternoon sector (12:00-18:00 MLT) the SWB scenario is more complicated (Chisham and Freeman, 2004). In the nightside and morning sectors the probability distribution of preferred SWB locations is characterised by a single well-defined latitudinal peak, whereas the probability distribution in the afternoon sector is characterised by multiple ill-defined latitudinal peaks. The lack of a single latitudinal peak is suggestive that there are SWBs being identified in this sector that represent physical transitions unrelated to the OCB.

The ability to accurately identify the OCB in the afternoon sector is important. Previous studies have used the afternoon sector SWB to determine the location and tilt of the OCB to enable the calculation of reconnection rates (Baker et al., 1997; Pinnock et al., 1999). Differences in the latitudes of SWBs observed either side of magnetic local noon have also been used to provide evidence for bifurcated reconnection sites on the dayside magnetopause which are predicted by the anti-parallel merging hypothesis (Coleman et al., 2001), and to determine the locations of these reconnection sites on the magnetopause (Chisham et al., 2002).

The aim of the present paper is to analyse statistically how the SWB relates to the OCB across the afternoon sector ionosphere, from noon (12:00 MLT) to dusk (18:00 MLT), and to determine if the SWB can be reliably used as a proxy in this sector. To this end, we compare the latitudes of SWBs measured in 5 years of data from 2 Northern Hemisphere SuperDARN radars with the latitudes of PPBs observed by DMSP low-altitude spacecraft at similar universal times (UTs) and MLTs. We also determine some rules for using the SWB in this MLT sector.

\section{Technique}

In this paper we make use of reliable algorithms which allow automated, objective identifications of SWBs in SuperDARN HF radar data and PPBs in DMSP particle precipitation data. We employ the "C-F threshold technique" to identify the SWB (Chisham and Freeman, 2003, 2004). The practical application of this technique is fully detailed in Chisham et al. (2004, 2005a). In brief, the technique involves choosing a spectral width threshold value and searching poleward through the spectral width measurements from a SuperDARN radar beam until this threshold is exceeded. The threshold value is chosen so that it lies approximately midway between the median values of the spectral width distributions found poleward and equatorward of the SWB. Hence, spectral width values above this threshold are more likely to originate from the distribution of spectral width values typically found poleward of the SWB than from those found equatorward of the SWB. The spectral width data are preprocessed before the application of this algorithm by spatial and temporal median filtering of the data. This preprocessing increases the accuracy of the estimated SWB location by effectively thinning the distributions of spectral width found poleward and equatorward of the SWB, making it easier to distinguish between them (Chisham and Freeman, 2003).

We have applied the C-F threshold technique to 5 years of spectral width data (1997-2001 inclusive) from the meridional beams of the Goose Bay (beam 4) and CUTLASS Finland (beam 7) SuperDARN radars. The SWB in meridional or near-meridional beams is generally the most accurate proxy for the OCB (Chisham et al., 2005b). We have used a spectral width threshold of $150 \mathrm{~m} / \mathrm{s}$ as this is approximately the mid-point between the median values of the spectral width distributions found poleward and equatorward of the SWB in the 12:00-18:00 MLT sector (Chisham and Freeman, 2004). The method of compilation of the boundary databases is described in detail in Chisham et al. (2005a). The Goose Bay and Finland radars were chosen for this study as the SWBs measured by these radars had the best overlap in time and space with the PPBs measured by the DMSP spacecraft in the 12:00-18:00 MLT sector (see Chisham et al. (2005a) for details). We have no reason to suspect that the results for the other SuperDARN radars would differ significantly from those presented here. To our knowledge, the varying geographic locations of the radars and HF radio propagation conditions only have small secondary effects on spectral width (especially if only meridional beams 
are considered). Furthermore, the results of Chisham et al. (2005a) showed that SWBs measured by SuperDARN radars at different longitudes, but in the same MLT sector were statistically co-incident.

We make use of PPB measurements from 5 DMSP spacecraft (F11-15), identified in precipitating particle measurements from the same 5-year interval (1997-2001). The boundaries we use are based on the automated dayside region identification algorithms outlined by Newell et al. (1991) and are determined using the method described in Sotirelis and Newell (2000). We use determinations of the following PPBs:

(1) deq, the equatorward boundary of diffuse precipitation.

(2) dds, the diffuse/structured precipitation boundary. This is located where there is an unambiguous transition from central plasma sheet (CPS) precipitation to boundary plasma sheet (BPS) precipitation and/or low-latitude boundary layer (LLBL) precipitation.

(3) doc, the open-closed field line boundary. This is located where there is an unambiguous transition between open and closed field line precipitation regions. CPS, BPS, and LLBL are taken to be closed, and cusp, mantle, open LLBL, polar rain, and void are considered to be open (see Newell and Meng (1998) for the difference between closed and open LLBL).

If any of these transitions are not clear, because of ambiguities in the region locations, then the transition is not added to the data set.

The data comparison technique is outlined in full detail in Chisham et al. (2004, 2005a). In brief, taking the SWBs for each radar in turn, each PPB observation was matched with the closest SWB obtained within \pm 10 mins UT of the PPB observation. The SWB observation must also have been within $\pm 1 \mathrm{~h}$ of MLT of the PPB observation to produce a matched boundary pair. For each matched pair, the difference between the two boundary latitudes was determined. Distributions of these latitude differences were determined for each radar by combining the results from all the matched pairs observed within the 5-year interval.

In this paper we also contrast the results measured during different prevailing IMF conditions. We use IMF data from the ACE spacecraft, lagged by an appropriate time $T$ to its time of interaction with the Earth's magnetosphere, using the approximation $T=X / V_{S W}$, where $X$ is the GSE x-coordinate of ACE and $V_{S W}$ is the solar wind velocity measured by ACE. This assumes that the IMF data measured upstream is a good representation of that which subsequently impinges the magnetosphere. The 5-year IMF database was reduced by defining one clock angle bin that best represented each $30 \mathrm{~min}$ segment of data. We considered 6 equally-sized clock angle bins, each covering a $60^{\circ}$ sector, centred on $-120^{\circ}$, $-60^{\circ}, 0^{\circ}, 60^{\circ}, 120^{\circ}$, and $180^{\circ}$ clock angle. The bin for each 30-min interval was chosen as that which contained the most 1-min data samples that comprised the interval. Additionally, we only used data intervals where $70 \%$ or more of the IMF data within that interval was within the selected clock angle bin. In this study we distinguish the results by northward
IMF (combining the 3 bins centred on $-60^{\circ}, 0^{\circ}$, and $60^{\circ}$ ) or southward IMF (combining the 3 bins centred on $-120^{\circ}$, $180^{\circ}$, and $120^{\circ}$ ), and by IMF $B_{y}<0$ (combining the 2 bins centred on $-120^{\circ}$ and $-60^{\circ}$ ) or IMF $B_{y}>0$ (combining the 2 bins centred on $120^{\circ}$ and $60^{\circ}$ ).

\section{Results}

3.1 Probability distribution of the SWBs with latitude and
MLT

By determining the probability distribution of the SWB with latitude and MLT, Chisham and Freeman (2004) showed how the preferred latitudinal location of SWBs in data measured by the Halley SuperDARN radar became less clearly defined in the afternoon sector ionosphere (see their Fig. 12). As we are using data from the Goose Bay and Finland SuperDARN radars in this study, we first present the equivalent latitudeMLT probability distributions for the SWB locations identified by the Goose Bay and Finland radars for the 5-year SWB database. Full details regarding the determination of these distributions are presented in Chisham and Freeman (2004) (see their Sec. 5). In brief, we determine the occurrence distribution of the measured SWB locations binned latitudinally by range gate and separated into $1-\mathrm{h}$ wide MLT bins. To reduce spurious range-to-range variability we apply a 5-range gate moving average filter to each MLT sector. We normalise the occurrence distribution at all range gates and MLTs by dividing by the occurrence distribution of the total number of possible boundaries that could have been measured at each location, for the complete 5-year data set (a function of the data coverage). This normalisation results in the true probability distribution of observed SWB locations.

In Fig. 1 we present the probability distributions of the SWB locations (determined using a $150 \mathrm{~m} / \mathrm{s}$ spectral width threshold) for Goose Bay (Fig. 1a) and Finland (Fig. 1b). For both radars there are clearly-defined preferred SWB latitudes at most MLTs. There is a single latitudinal peak which varies continuously with MLT across the morning and nightside sectors. However, the afternoon sector (12:0018:00 MLT) consistently displays more than one significant latitudinal peak. At Goose Bay (Fig. 1a) this takes the form of two clearly defined peaks, one reaching a maximum at $\sim 78^{\circ}-79^{\circ}$ and the other at $\sim 72^{\circ}$ with a minimum between them at $\sim 75^{\circ}$. At Finland (Fig. 1b) the afternoon sector picture is less ordered. There is still a clear high latitude peak, although its location varies from $\sim 75^{\circ}$ to $\sim 80^{\circ}$ from noon through to dusk. The lower latitude peak is less clearly defined and peaks occur from $\sim 68^{\circ}$ to $\sim 74^{\circ}$.

The results in this sector clearly suggest that a difference may exist between the SWBs measured between 12:00 and 18:00 MLT, and those measured at other MLTs. The double/multiple peaked nature of the probability distributions suggests that the SWBs in this sector result from more than one physical latitudinal transition. This implies that the SWBs measured in this region may not always be a good 

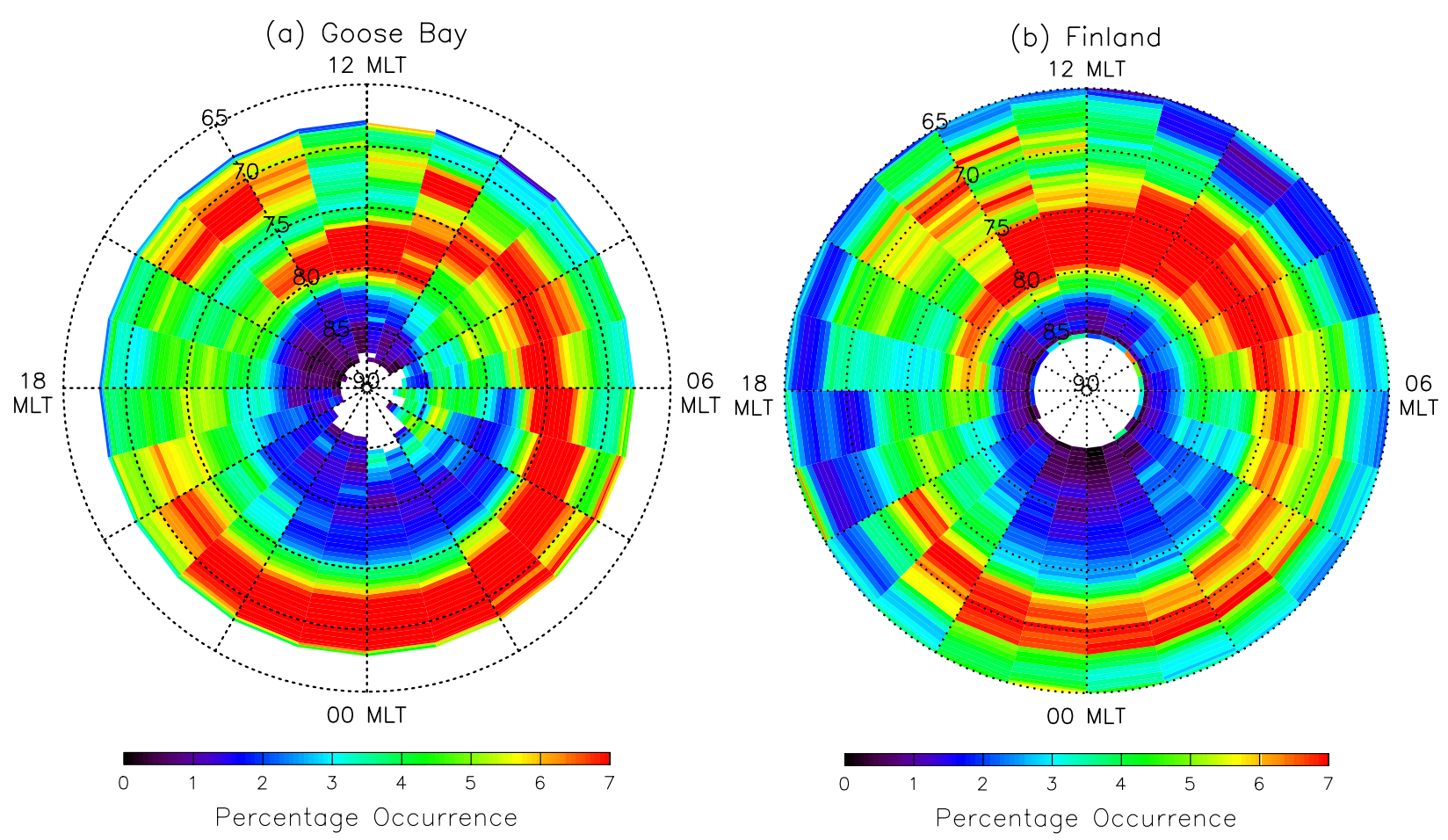

Fig. 1. The probability distributions of the observed SWB locations determined within the 5-year databases for the (a) Goose Bay, and (b) Finland SuperDARN radars, using the C-F threshold technique, smoothed by the application of a 5-range gate moving average. The distributions are presented in AACGM latitude and MLT space.

proxy for the OCB. Following these observations we divide our SWB data into two latitudinal bins (poleward and equatorward of $74^{\circ}$ AACGM latitude) and study the boundaries in each of these bins separately.

A point of note here, although unrelated to the afternoon sector distribution, is the occurrence of a secondary thin latitudinal peak in the morning sector between 02:00 and 06:00 MLT. This occurs in the results for both the Goose Bay and Finland radars spreading across approximately $1^{\circ}$ of latitude from $68^{\circ}-69^{\circ}$ AACGM latitude. This is unlikely to be an instrumental effect as it is observed at different ranges by the two radars. As yet, we have no explanation for this feature.

\subsection{SWB-PPB latitude difference distributions}

In Fig. 2 we present the occurrence distributions of the latitudinal differences between the different PPB types and the $150 \mathrm{~m} / \mathrm{s}$ threshold SWB for both the Goose Bay (Fig. 2a) and Finland (Fig. 2b) SuperDARN radars using measurements from the 12:00-18:00 MLT sector. The top panels of each figure present the results when considering the SWBs measured poleward of $74^{\circ}$ AACGM latitude. The lower panels present the results when considering the SWBs measured equatorward of $74^{\circ}$ AACGM latitude. The distributions have a latitudinal resolution of $2^{\circ}$ and are presented relative to the SWB location (dashed vertical line at zero latitude difference). The comparisons have been made for the deq (black), dds (yellow), and doc (red) boundaries.

The results from the Goose Bay and Finland radars show the same pattern. Poleward of $74^{\circ}$ the distributions are very similar to those observed in the late morning sector $(\sim 08: 00-$ 12:00 MLT) (Chisham et al., 2005a) and also to the results for equivalent PPBs observed in the evening sector (18:0002:00 MLT) (Chisham et al., 2004). The deq (black) boundary distributions are located well equatorward of the SWB, peaking at $\sim 8^{\circ}$ equatorward. There is no overlap of these distributions with the location of the SWB. The dds (yellow) boundary distributions are also located equatorward of the SWB, peaking at $\sim 4^{\circ}-6^{\circ}$ equatorward. Again, there is virtually no overlap of these distributions with the SWB. The doc (red) boundary distributions both peak at zero latitude difference (although there is a negative skew in the Finland distribution).

Equatorward of $74^{\circ}$ the distributions are very different to those described above. Although the statistical sample of these events is smaller, the distributions are still well defined. Both the deq (black) and dds (yellow) distributions are still located equatorward of the SWB, peaking at $\sim 2^{\circ}-6^{\circ}$ equatorward of the SWB, but the distributions now show some overlap with the SWB location. More significantly, the doc (red) boundary distribution has moved so that its peak is located $\sim 4^{\circ}-6^{\circ}$ poleward of the SWB, the distributions showing a similar amount of overlap with the SWB as the 

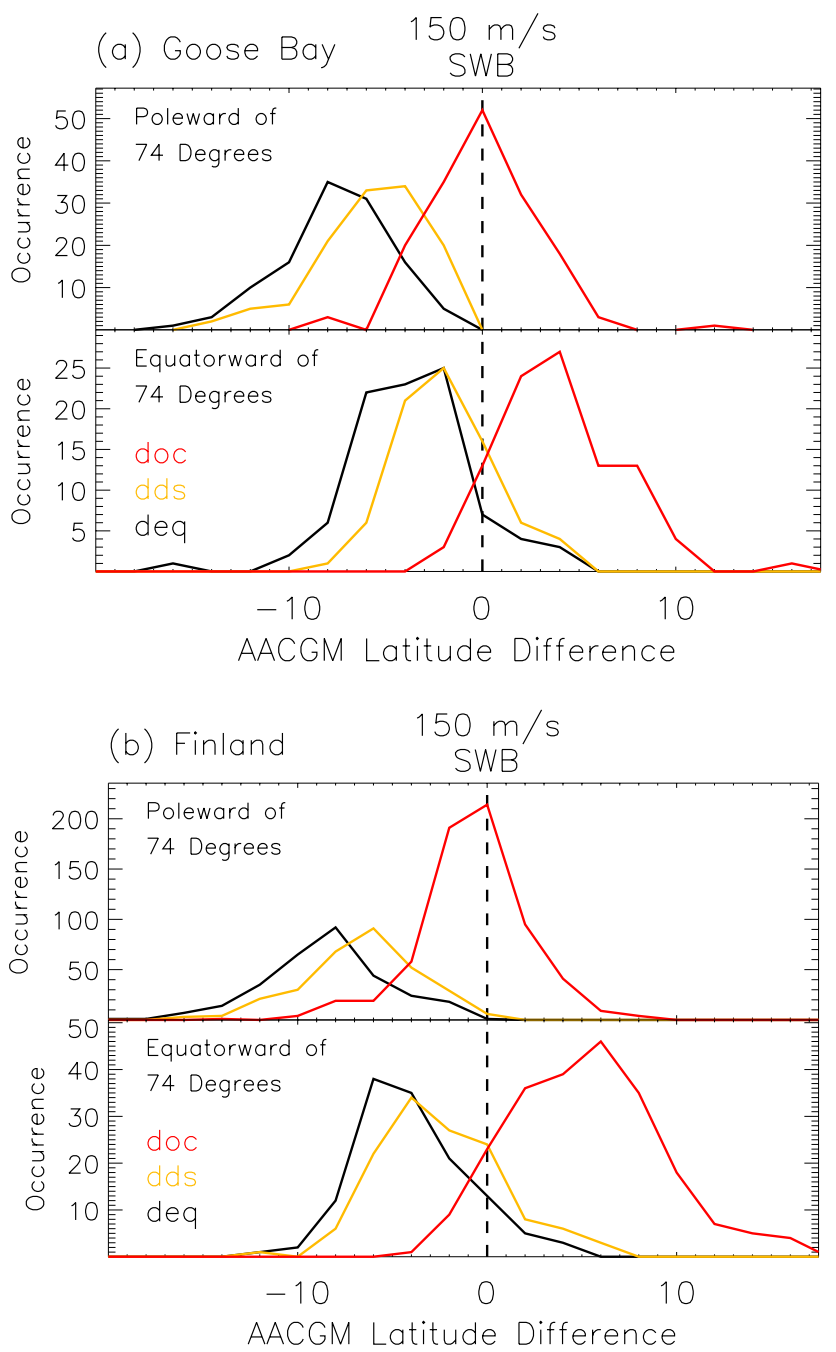

Fig. 2. Occurrence distributions of latitude differences between the DMSP PPBs and the $150 \mathrm{~m} / \mathrm{s}$ threshold SWB for the (a) Goose Bay, and (b) Finland SuperDARN radars in the 12:00-18:00 MLT region. The upper panels represent the results from comparisons using SWBs located poleward of $74^{\circ}$, whereas the lower panels represent the results from comparisons using SWBs located equatorward of $74^{\circ}$. The three different distributions in each panel are for the different PPBs: deq (black), dds (yellow), and doc (red).

deq and dds boundaries. These results suggest that the SWBs being identified equatorward of $74^{\circ}$ are unrelated to the OCB and that they correspond to another latitudinal transition that exists in the BPS/LLBL precipitation region.

\subsection{Explaining the shape of the difference distributions}

To investigate this further, we plot in Fig. 3 the latitudinal distributions of the different boundaries. The upper panel in Fig. 3 presents the results for matched pairs when the SWB is observed poleward of $74^{\circ}$, whereas the lower panel presents the results for matched pairs when the SWB is observed equatorward of $74^{\circ}$. The red lines describe the probability distributions of the SWBs from matched pairs (both fall to

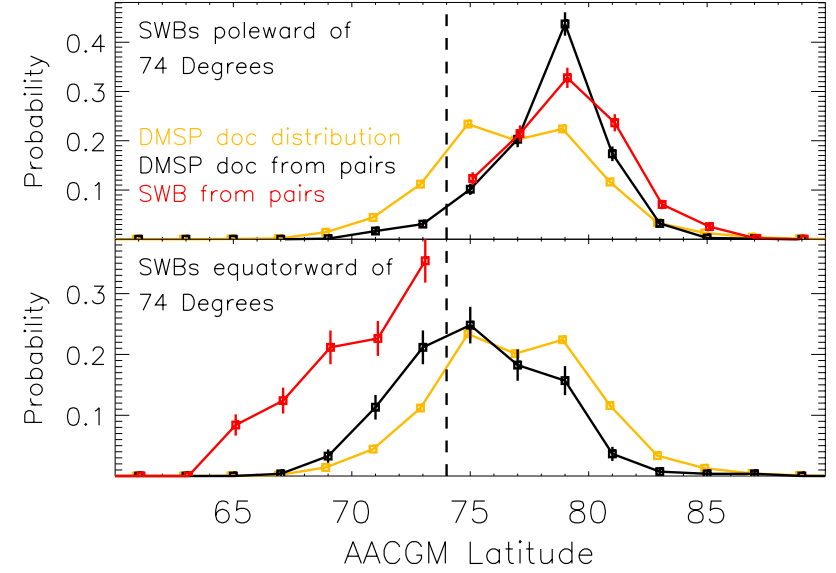

Fig. 3. Latitudinal probability distributions of boundary occurrence in the 12:00-18:00 MLT region. The red lines represent the latitude distributions of the SWBs that form matched pairs with DMSP doc boundary observations. Results from the Goose Bay and Finland SuperDARN radars have been combined. The black lines represent the latitude distributions of DMSP doc boundary observations from the same matched pairs. The yellow lines represent the latitude distribution of all DMSP doc boundary observations made during the 5-year interval (1997-2001). The upper panel represents the results from matched pairs where the SWBs are located poleward of $74^{\circ}$, whereas the lower panel represents the results from matched pairs where the SWBs are located equatorward of $74^{\circ}$. The vertical dashed line highlights the location of $74^{\circ}$ AACGM latitude.

zero at $74^{\circ}$ latitude by definition). In the upper panel, this distribution peaks at $79^{\circ}$ latitude. In the lower panel, this distribution increases with increasing latitude until its cutoff point at $74^{\circ}$ latitude. The black lines describe the probability distributions of DMSP doc boundaries from matched pairs. In the upper panel, this distribution also peaks at $79^{\circ}$ latitude and matches very closely to the SWB distribution, strongly supporting the results presented in previous figures that the two boundaries are statistically co-located. In the lower panel, in contrast to the SWB distribution, most of the DMSP doc distribution is located poleward of $74^{\circ}$. There is no sign of a fall off in the distribution poleward of $74^{\circ}$ as would be expected if the SWB and DMSP doc boundaries were co-located in this region. For reference, we also plot the DMSP doc boundary parent distribution (yellow line). This is determined from all the DMSP doc observations made in the 5-year interval. (The double peaked nature of the parent distribution is likely to be a result of the uneven spatial coverage of the spacecraft orbits.) In the lower panel it is very evident that the DMSP doc matched pairs distribution approximates more to the parent distribution than the SWB distribution, suggesting that the matched pair distribution mostly represents a random sample from the parent distribution and hence has little association with the SWB distribution.

These results suggest that the difference distributions (and indeed all the difference distributions of this type) can be 


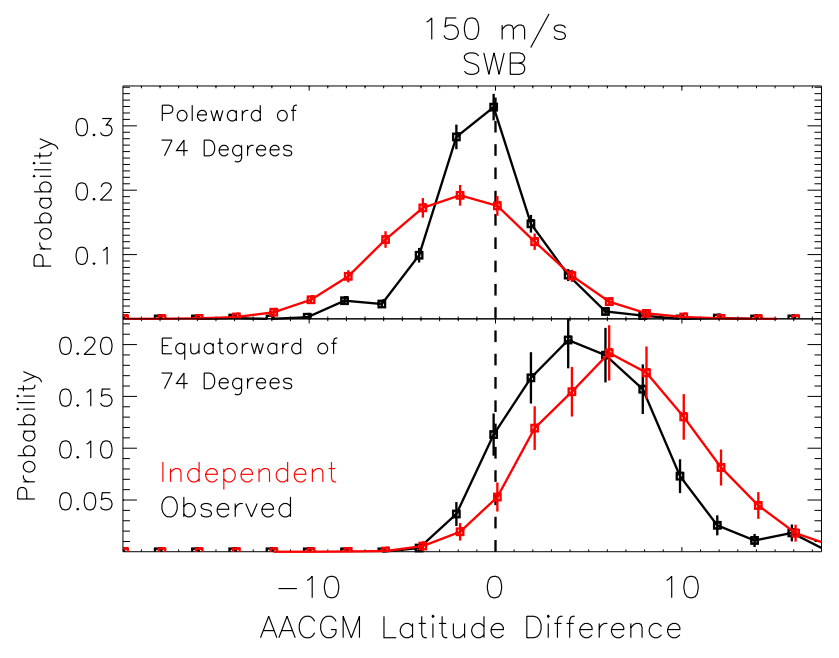

Fig. 4. Probability distributions of latitude differences between the DMSP doc boundary and the $150 \mathrm{~m} / \mathrm{s}$ threshold SWB for the combined Goose Bay and Finland SuperDARN radars in the 12:0018:00 MLT region. The upper panel represents the results from comparisons using SWBs located poleward of $74^{\circ}$, whereas the lower panel represents the results from comparisons using SWBs located equatorward of $74^{\circ}$. The black distributions represent the observed distributions. The red distributions represent the predicted distributions that would occur if the SWB and DMSP doc observations were independent.

simply described as a combination of results when the SWB is co-located with the OCB, and results when the SWB is unrelated to the OCB. The balance between these two scenarios determines the shape of the difference distributions. When the SWB is unrelated to the OCB then difference distributions should follow the convolution of the SWB latitude distribution with the parent DMSP doc distribution and the DMSP doc matched pair distribution should match the parent distribution. When the SWB is co-located with the OCB then the SWB latitude distribution should follow the DMSP doc matched pair distribution and the difference distribution will be a $\delta$-function at zero difference. In reality, due to the errors in the measurement techniques (as discussed in Chisham et al. (2005a)), this will be the convolution of a Gaussian function resulting from random measurement errors with a $\delta$-function at zero difference.

In Fig. 4 we present the latitude difference distributions combining the results from the Goose Bay and Finland radars (black lines). The upper panel again presents the results for SWBs measured poleward of $74^{\circ}$ latitude, whereas the lower panel presents the results for SWBs measured equatorward of $74^{\circ}$ latitude. The observed distributions are obviously very similar to those presented in Fig. 2. In Fig. 4 we also present the convolved distributions of the SWB latitude distributions with the parent DMSP doc distribution (red lines). These difference distributions represent the expected result if the SWB and DMSP doc boundary observations were independent.

In the top panel, the observed distribution matches closer to a Gaussian function at zero difference than to the

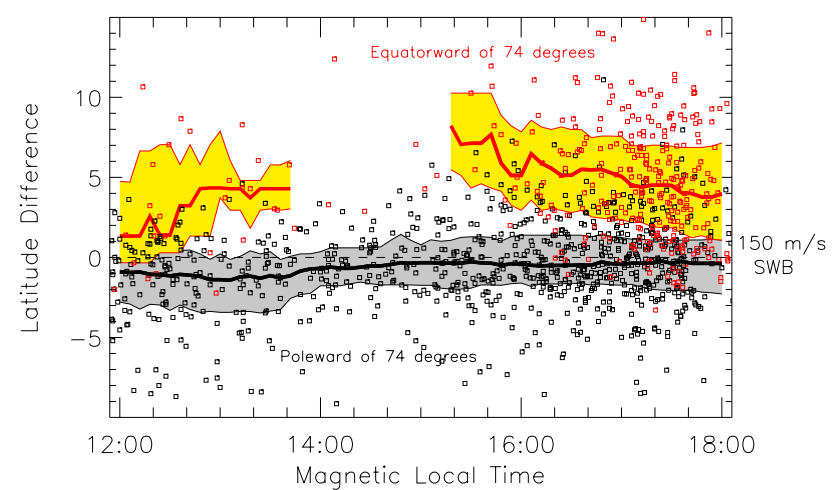

Fig. 5. Latitude differences between the $150 \mathrm{~m} / \mathrm{s}$ threshold SWB and the doc PPB measured in the afternoon sector (12:0018:00 MLT). The black symbols represent the difference values at the times when the SWB was identified poleward of $74^{\circ}$. The red symbols represent the difference values at the times when the SWB was identified equatorward of $74^{\circ}$. The dashed horizontal line at zero difference represents the location of the SWB. The bold black line and shaded grey area represent the spatial variation of the median and quartile range, respectively, of the latitude differences measured poleward of $74^{\circ}$. The bold red line and shaded yellow area represent the spatial variation of the median and quartile range, respectively, of the latitude differences measured equatorward of $74^{\circ}$.

independent distribution suggesting that the distribution is dominated by SWBs that are co-located with the OCB. However, the skew to the observed distribution could be explained by some of the observed SWBs being unrelated to the OCB, i.e., the observed distribution has some contamination from the independent distribution. This could also explain the latitude difference distribution skews typically observed in previous studies (Chisham et al., 2004, 2005a).

In the bottom panel, the observed distribution matches closer to the independent distribution than to a Gaussian function at zero difference. This suggests that the distribution is dominated by SWBs that are unrelated to the OCB. The slight shift of the observed distribution towards the zero difference is probably a result of "contamination" by a small number of observations where the SWB is a good proxy for the OCB.

\subsection{Variability with MLT}

The distributions presented in Fig. 2 provide no information about the variation of the data comparison results with MLT. The double-peaked probability distribution of SWB latitude is clear from 13:00-16:00 MLT in Fig. 1a but less clear at other MLTs. Also, Chisham et al. (2005a) found that the median of the latitude difference distribution varies significantly with MLT in the morning sector. Hence, identifying any variations with MLT in the afternoon sector is important.

In order to show the variation in latitude difference with MLT, we plot all the difference results for the doc boundaries 
in Fig. 5. Each symbol represents the latitudinal difference for a single matched pair. The symbols are colour-coded by latitudinal location of the SWB; the black symbols represent the results for SWBs measured poleward of $74^{\circ}$ whereas the red symbols represent the results for the SWBs measured equatorward of $74^{\circ}$. The horizontal dashed line at zero latitude difference marks the location of the $150 \mathrm{~m} / \mathrm{s}$ threshold SWB. The bold black line and grey shaded region show the MLT variation of the median and quartile range, respectively, of the latitude difference distribution poleward of $74^{\circ}$. The bold red line and yellow shaded region show the MLT variation of the median and quartile range, respectively, of the latitude difference distribution equatorward of $74^{\circ}$. The median and quartile range variations were calculated using a sliding 1-h MLT window. A minimum of 10 points was required in a window to provide a median estimate.

There are clear differences between the median values in the two latitude regions, as would be expected from the results presented in Fig. 2. For the SWBs measured poleward of $74^{\circ}$ the median value of the distribution is located within $1^{\circ}$ of zero latitude difference for the whole region from 12:00 to 18:00 MLT. The slight negative shift of this line matches the negative skew of the distribution measured by the Finland radar, as shown in Fig. 2b and explained in the discussion of Fig. 4. However, the closeness to zero suggests that the SWBs measured at the higher latitudes are good proxies for the OCB across the whole MLT range. For the SWBs measured equatorward of $74^{\circ}$, the median value of the distribution is located at $\sim 4^{\circ}-7^{\circ}$ latitude difference (meaning that the OCB is typically located significantly poleward of the SWB). This suggests that the SWBs being identified at the lower latitudes are almost always unrelated to the OCB across the whole MLT range (although there are very few matched pairs at low latitudes in the 12:00 to 16:00 MLT range due to the restrictions of the DMSP orbits).

\subsection{Variability with IMF direction}

It is well known that the size of the polar cap, and hence the latitudinal location of the OCB in the ionosphere, is highly correlated with the magnitude and direction of the IMF. The OCB latitude is typically higher during intervals of northward IMF which are characterised by smaller polar cap regions (Newell et al., 1989). It is also well-known that the spatial distribution of backscatter from the SuperDARN radars varies with the prevailing IMF direction, the backscatter typically extending to much lower latitudes during intervals of southward IMF. Assessing whether the low-latitude SWBs (those that appear unrelated to the OCB) are typical during all prevailing IMF conditions, or whether they occur preferentially during a particular IMF condition, will constrain theories for the origin of these low-latitude SWBs.

In Fig. 6 we present the latitude difference distributions for the afternoon sector separated for northward and southward IMF conditions. These distributions are compiled from only a subset of the matched pairs used to compile the results in Fig. 2, as explained in Sec. 2 (only intervals characterised

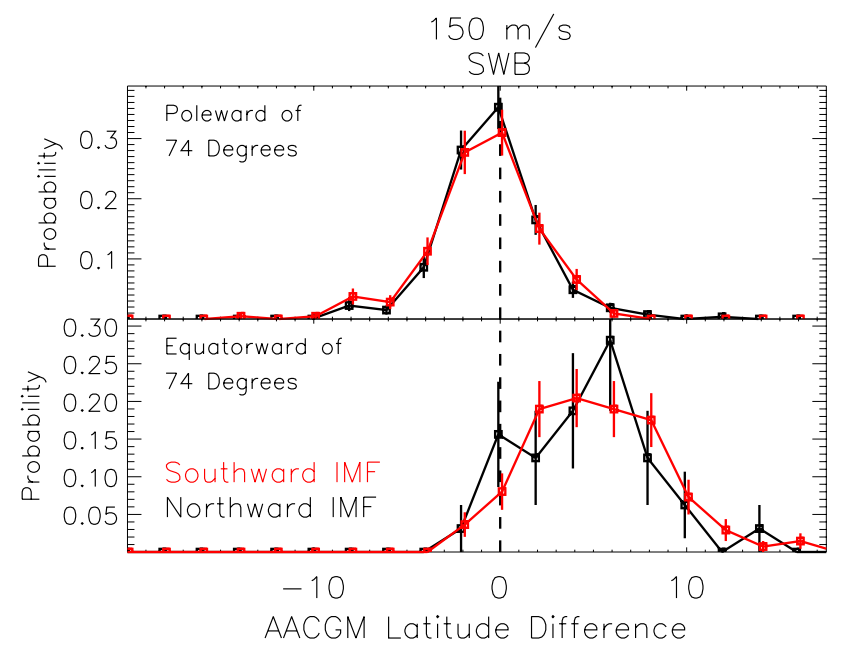

Fig. 6. Probability distributions of latitude differences between the DMSP doc boundary and the $150 \mathrm{~m} / \mathrm{s}$ threshold SWB for the combined Goose Bay and Finland SuperDARN radars in the 12:0018:00 MLT region. The upper panel represents the results from comparisons using SWBs located poleward of $74^{\circ}$, whereas the lower panel represents the results from comparisons using SWBs located equatorward of $74^{\circ}$. The black distributions represent the results measured during intervals of prevailing northward IMF conditions, whereas the red distributions represent the results measured during intervals of prevailing southward IMF conditions.

by an unambiguous IMF direction were used). Hence, to increase the statistical reliability of the distributions, Fig. 6 presents the results for the Goose Bay and Finland radars combined. The distributions are presented as probabilities because different numbers of events were observed for the different IMF orientations. The panels in Fig. 6 are structured as in Fig. 2, the top panel shows the distributions when considering the SWBs measured poleward of $74^{\circ}$ AACGM latitude, whereas the lower panel shows the distributions when considering the SWBs measured equatorward of $74^{\circ}$ AACGM latitude. The error bars represent the standard error in the measurements, the larger error bars in the lower panel reflecting the fewer number of events observed equatorward of $74^{\circ}$ latitude.

The two distributions for the results poleward of $74^{\circ}$ (top panel) are very similar, strongly suggesting that there are no differences between the accuracy of SWBs measured during northward and southward IMF conditions. The two distributions for the results equatorward of $74^{\circ}$ (bottom panel) show more differences, but agree to within the uncertainties of the measurements. The statistical reliability of the small-scale variations in the northward IMF distribution is in question due to the small number of events involved (highlighted by the large error bars). Hence, there appear to be no significant differences between the latitudinal difference distributions observed during northward and southward IMF conditions. The majority of the SWBs measured equatorward of $74^{\circ}$ latitude occur during southward IMF conditions. However, this is most likely to be an effect resulting from 


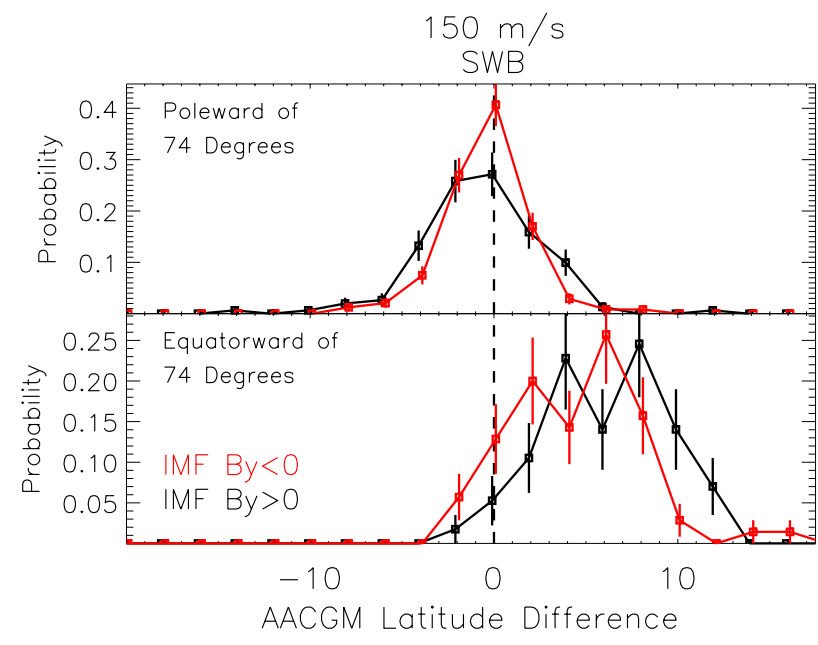

Fig. 7. Probability distributions of latitude differences between the DMSP doc boundary and the $150 \mathrm{~m} / \mathrm{s}$ threshold SWB for the combined Goose Bay and Finland SuperDARN radars in the 12:0018:00 MLT region. The upper panel represents the results from comparisons using SWBs located poleward of $74^{\circ}$, whereas the lower panel represents the results from comparisons using SWBs located equatorward of $74^{\circ}$. The black distributions represent the results measured during intervals of IMF $B_{y}>0$, whereas the red distributions represent the results measured during intervals of IMF $B_{y}<0$.

the distribution of SuperDARN radar backscatter rather than a result of an underlying physical phenomena which exists only during southward IMF conditions.

In Fig. 7 we present latitude difference distributions similar to those presented in Fig. 6 although here we separate the data for IMF $B_{y}<0$ and IMF $B_{y}>0$ conditions. The position of the polar cap is affected by the IMF $B_{y}$ component, in the Northern Hemisphere being shifted towards dawn (dusk) during intervals when IMF $B_{y}>0\left(B_{y}<0\right)$ (Cowley et al., 1991). Hence, our cutoff latitude of $74^{\circ}$ in the afternoon sector will have a different average offset from the OCB for the different senses of IMF $B_{y}$, being typically closer to the OCB during IMF $B_{y}<0$ intervals. During these IMF $B_{y}<0$ intervals the true cutoff latitude will be on average equatorward of $74^{\circ}$ and so the distribution of latitude differences equatorward of $74^{\circ}$ will contain more instances when the SWB is a good proxy for the OCB. Conversely, during IMF $B_{y}>0$ intervals the true cutoff latitude will be on average poleward of $74^{\circ}$ and so the distribution of latitude differences poleward of $74^{\circ}$ will contain more instances when the SWB is a poor proxy for the OCB. The consequences of these features are clear in Fig. 7. Poleward of $74^{\circ}$ the IMF $B_{y}<0$ distribution (red) clearly peaks at zero latitude difference, whereas the IMF $B_{y}>0$ distribution (black) is shifted slightly to negative latitude differences (i.e., toward the independent distribution, see Fig. 4), demonstrating an increase in the number of times that the SWB is a poor proxy for the OCB. Equatorward of $74^{\circ}$ the IMF $B_{y}<0$ distribution (red) is shifted slightly toward the zero latitude difference (i.e., away from the independent distribution, see Fig. 4), demonstrating an increase in the number of times that the SWB is a good proxy for the OCB. Hence, the differences between the difference distributions measured for the two IMF $B_{y}$ states can be fully explained by the shift in the average polar cap position during these intervals.

\section{Discussion and conclusions}

The results presented above show that SWBs measured poleward of $\sim 74^{\circ}$ AACGM latitude, in the afternoon sector (12:00-18:00 MLT), are statistically co-located with the OCB as measured by the DMSP spacecraft, with $76 \%$ of SWBs lying within $3^{\circ}$ of the OCB. The width of the latitudinal difference distributions might suggest that, although there is a good statistical relationship between the two boundaries, the SWB might not be a wholly reliable proxy on a case-tocase basis. However, this would be misleading. Much of the observed spread in the distributions is due to the use of the finite (1-h) MLT window in the data comparisons. Reducing the size of this MLT window decreases the width of the difference distributions, as discussed in Chisham et al. $(2004,2005 a)$. Other uncertainties in the measurements such as failure of the PPB determination algorithm, failure of the SWB determination algorithm, and errors in the mapping of the two data sets will lead to random errors in the data set which result in the Gaussian-like spread of the difference distributions. All these measurement uncertainties are discussed in detail in Chisham et al. (2005a). There are no systematic offsets of the SWB from the OCB in the afternoon sector ionosphere such as those observed by Chisham et al. (2005a) in the morning sector ionosphere. Due to the large amount of data samples used in this analysis, the uncertainty in the mean value of the difference distribution is very small (assuming random errors to be the cause of the Gaussian spread). Hence, we would argue that the uncertainty of the OCB location determined from SWB measurements is similar to that of the measurement of the SWB location itself, which is $<\sim 1^{\circ}$ latitude (Chisham and Freeman, 2003).

In contrast to the SWBs measured poleward of $74^{\circ}$, SWBs measured equatorward of $\sim 74^{\circ}$ AACGM latitude have a poor statistical correlation with the OCB with only $32 \%$ of SWBs lying within $3^{\circ}$ of the OCB. This is not much greater than the $19 \%$ that would be expected if the SWBs were randomly distributed with latitude. These results suggest that there is some physical process which is resulting in high spectral width values in the lower-latitude closed field line regions of the ionosphere. This in turn is resulting in the detection of the lower-latitude SWBs. Any physical mechanism to explain this spectral width "anomaly" needs to abide by the following constraints:

(1) It needs to be most prevalent in the afternoon sector ionosphere ( 12:00-18:00 MLT). It is only in this MLT sector that we consistently see more than one latitudinal peak in the probability distributions of the observed SWBs (see Fig. 1). 
(2) It needs to be located on closed field lines, some distance equatorward of the OCB, but unrelated to it. The results presented in Fig. 4 strongly suggest that the locations of these lower latitude SWBs are independent of the location of the OCB.

(3) It must have some characteristic that would lead to the production of high spectral width values.

The localisation to the afternoon sector suggests a mechanism which causes asymmetry between the morning and afternoon sector ionospheres. Often, the sense of the IMF $B_{y}$ component can be the source of such asymmetries. However, when we divide our results according to IMF $B_{y}$ we see no evidence of increased lower-latitude SWBs unrelated to the OCB for either sense of IMF $B_{y}$. This rules out mechanisms that might be associated with one sense of IMF $B_{y}$, such as a relationship with a particular convection orientation or with the afternoon sector ridge of ionisation (Pinnock et al., 1995).

One possible reason for the existence of high spectral width values at low latitudes is as a result of the particle precipitation characteristics of the region. Chisham et al. (2005a) provided evidence that regions of high spectral width in the ionosphere correlate with regions of low electron energy flux. Newell et al. (2004) showed that the precipitating electron energy flux reduces dramatically in the afternoon sector (12:00-18:00 MLT) at $\sim 6^{\circ}-8^{\circ}$ equatorward of the OCB, to levels of electron energy flux typically found in the cusp and mantle regions on open field lines. Thus, we might expect to observe high spectral width values at these low latitudes in the afternoon sector and this should lead to the existence of low-latitude SWBs below the OCB and possibly unassociated with it.

The detection of low-latitude SWBs unassociated with the OCB requires modification of the " $\mathrm{C}-\mathrm{F}$ threshold technique" to overcome the problem of boundary misidentifications. Chisham and Freeman (2004) outlined in detail the 5-point algorithm for the C-F threshold technique. In this algorithm the poleward search up a beam concludes with the identification of a valid SWB if two criteria are satisfied (steps 4 and 5 in Chisham and Freeman (2004)):

(1) The median-filtered spectral width value for range $k$ and beam $j$ is greater than the chosen threshold $c\left(\bar{w}_{k, j}^{n}>c\right)$.

(2) The median of the three values poleward of this also needs to be greater than the chosen threshold value $\left(\right.$ Median $\left.\left[\bar{w}_{k+1, j}^{n}, \bar{w}_{k+2, j}^{n}, \bar{w}_{k+3, j}^{n}\right]>c\right)$.

In order to be able to identify SWBs associated with the OCB in MLT regions where low-latitude SWBs exist, the algorithm needs to continue searching along a beam for further potential SWBs after a SWB has been identified rather than terminating the search at the first SWB. In cases where more than one SWB is determined, the SWB which best matches the OCB location needs to be determined either by inspection or by rating the SWB determinations in some way. The best method for easily determining which would be the true SWB is presently unclear and requires further thought and analysis.

Any modification to the technique must also address the problem identified by Chisham and Freeman (2004) of occasional boundary misidentifications when there is no low spectral width region equatorward of an isolated high spectral width region. In this scenario the present technique will occasionally identify a SWB within the high spectral width region as it only requires one low spectral width value below the spectral width threshold to form the low-latitude spectral width marker needed equatorward of the SWB. This problem is exacerbated by allowing the identification of multiple SWBs along a beam. To overcome this problem the algorithm needs to explicitly consider the low spectral width region equatorward of the SWB. We suggest that this is best achieved by requiring that for a SWB candidate to be valid, the median of the three median-filtered spectral width values equatorward of the boundary must be less than the chosen threshold (Median $\left[\bar{w}_{k-1, j}^{n}, \bar{w}_{k-2, j}^{n}, \bar{w}_{k-3, j}^{n}\right]<c$ ) in addition to the present rules quoted above. This should reduce the likelihood of such misidentifications.

In summary, by correlating 5 years of SWBs measured by the SuperDARN HF radar network with PPBs measured by the DMSP spacecraft, we have gained a better understanding of the relationship of the SWB with the OCB in the afternoon sector ionosphere. SWBs identified at high latitudes correlate well with the OCB and hence, can be regarded as good proxies. Specifically, poleward of $74^{\circ}$ AACGM latitude, $76 \%$ of SWBs lie within $3^{\circ}$ of the OCB. SWBs identified at lower latitudes correlate poorly with the OCB location and hence, should not be used as proxies for the OCB. Equatorward of $\sim 74^{\circ}$ AACGM latitude only $32 \%$ of SWBs lie within $3^{\circ}$ of the OCB. We have proposed that high spectral width values that are observed in closed field line regions in the afternoon sector are associated with the low level of precipitating electron energy flux that is typical of this region.

Acknowledgements. CUTLASS is supported by the PPARC (UK), the Swedish Institute for Space Physics, Uppsala, and the FMI, Helsinki, Finland. Support for the Goose Bay radar is provided in part by the NSF (USA), and in part by NASA (USA). The DMSP particle detectors were designed by D. Hardy of AFRL (USA), and data obtained from JHU/APL (USA). We thank D. Hardy, F. Rich, and P.T. Newell for their use. The ACE data are part of the CDAWeb database. We are grateful to N.F. Ness, principal investigator on the ACE MFI instrument.

Topical Editor M. Pinnock thanks W. Bristow and another referee for their help in evaluating this paper.

\section{References}

André, R., Pinnock, M., Villain, J.-P., and Hanuise, C.: Influence of magnetospheric processes on winter HF radar spectra characteristics, Ann. Geophys., 20, 1783-1793, 2002,

SRef-ID: 1432-0576/ag/2002-20-1783.

Baker, K. B., Dudeney, J. R., Greenwald, R. A., Pinnock, M., Newell, P. T., Rodger, A. S., Mattin, N., and Meng, C.-I.: HF radar signatures of the cusp and low-latitude boundary layer, J. Geophys. Res., 100, 7671-7695, 1995.

Baker, K. B., Rodger, A. S., and Lu, G.: HF-radar observations of the dayside magnetic merging rate: A Geospace Environment Modeling boundary layer campaign study, J. Geophys. Res., 102, 9603-9617, 1997. 
Carbary, J. F., Sotirelis, T., Newell, P. T., and Meng, C.-I.: Auroral boundary correlations between UVI and DMSP, J. Geophys. Res., 108, 1018, doi:10.1029/2002JA009378, 2003.

Chisham, G., Pinnock, M., Coleman, I. J., Hairston, M. R., and Walker, A. D. M: An unusual geometry of the ionospheric signature of the cusp: Implications for magnetopause merging sites, Ann. Geophys., 20, 29-40, 2002,

SRef-ID: 1432-0576/ag/2002-20-29.

Chisham, G., and Freeman, M. P.: A technique for accurately determining the cusp-region polar cap boundary using SuperDARN HF radar measurements, Ann. Geophys., 21, 983-996, 2003,

SRef-ID: 1432-0576/ag/2003-21-983.

Chisham, G., Freeman, M. P., and Sotirelis, T.: A statistical comparison of SuperDARN spectral width boundaries and DMSP particle precipitation boundaries in the nightside ionosphere, Geophys. Res. Lett., 31, L02804, doi:10.1029/2003GL019074, 2004.

Chisham, G. and Freeman, M. P.: An investigation of latitudinal transitions in the SuperDARN Doppler spectral width parameter at different magnetic local times, Ann. Geophys., 22, 1187-1202, 2004,

SRef-ID: 1432-0576/ag/2004-22-1187.

Chisham, G., Freeman, M. P., Sotirelis, T., Greenwald, R. A., Lester, M., and Villain, J.-P.: A statistical comparison of SuperDARN spectral width boundaries and DMSP particle precipitation boundaries in the morning sector ionosphere, Ann. Geophys., 23, 733-743, 2005a,

SRef-ID: 1432-0576/ag/2005-23-733.

Chisham, G., Freeman, M. P., Sotirelis, T., and Greenwald, R. A.: The accuracy of using the spectral width boundary measured in off-meridional SuperDARN HF radar beams as a proxy for the open-closed field line boundary, Ann. Geophys., 23, 2599-2604, 2005b,

SRef-ID: 1432-0576/ag/2005-23-2599.

Coleman, I. J., Chisham, G., Pinnock, M., and Freeman, M. P.: An ionospheric convection signature of antiparallel merging, J. Geophys. Res., 106, 29 995-29 007, 2001.

Cowley, S. W. H., Morelli, J. P., and Lockwood, M.: Dependence of convective flows and particle precipitation in the high-latitude dayside ionosphere on the $\mathrm{X}$ and $\mathrm{Y}$ components of the interplanetary magnetic field, J. Geophys. Res., 96, 5557-5564, 1991.

Cowley, S. W. H. and Lockwood, M.: Excitation and decay of solar wind-driven flows in the magnetosphere-ionosphere system, Ann. Geophys., 10, 103-115, 1992.

Greenwald, R. A., Baker, K. B., Dudeney, J. R., Pinnock, M., Jones, T. B., Thomas, E. C., Villain, J.-P., Cerisier, J.-C., Senior, C., Hanuise, C., Hunsucker, R. D., Sofko, G., Koehler, J., Nielsen, E., Pellinen, R., Walker, A. D. M., Sato, N., and Yamagishi, H.: DARN/SuperDARN: A global view of the dynamics of highlatitude convection, Space Sci. Rev., 71, 761-796, 1995.

Milan, S. E., Lester, M., Cowley, S. W. H., Oksavik, K., Brittnacher, M., Greenwald, R. A., Sofko, G., and Villain, J.-P.: Variations in the polar cap area during two substorm cycles, Ann. Geophys., 21, 1121-1140, 2003,

SRef-ID: 1432-0576/ag/2003-21-1121.
Milan, S. E., Cowley, S. W. H., Lester, M., Wright, D. M., Slavin, J. A., Fillingim, M., Carlson, C. W., and Singer, H. J.: Response of the magnetotail to changes in the open flux content of the magnetosphere, J. Geophys. Res., 109, A04220, doi:10.1029/2003JA010350, 2004.

Moorcroft, D. R.: The shape of auroral backscatter spectra, Geophys. Res. Lett., 31, L09802, doi:10.1029/2003GL019340, 2004.

Newell, P. T., Meng, C.-I., Sibeck, D. G., and Lepping, R.: Some low-altitude cusp dependencies on the interplanetary magnetic field, J. Geophys. Res., 94, 8921-8927, 1989.

Newell, P. T., Burke, W. J., Sanchez, E. R., Meng, C.-I., Greenspan, M. E., and Clauer, C. R.: The low-latitude boundary layer and the boundary plasma sheet at low altitude: Prenoon precipitation regions and convection reversal boundaries, J. Geophys. Res., 96, 21013-21023, 1991.

Newell, P. T. and Meng, C.-I.: Open and closed low latitude boundary layer, in: Polar Cap Boundary Phenomena, edited by: Moen, J., Egeland, A., and Lockwood, M., Kluwer Acad., Norwell, Mass., 91-101, 1998.

Newell, P. T., Ruohoniemi, J. M., and Meng, C.-I.: Maps of precipitation by source region, binned by IMF, with inertial convection streamlines, J. Geophys. Res., 109, A10206, doi:10.1029/2004JA010499, 2004.

Parkinson, M. L., Chisham, G., Pinnock, M., Dyson, P. L., and Devlin, J. C.: Magnetic local time, substorm, and particle precipitation-related variations in the behaviour of SuperDARN Doppler spectral widths, Ann. Geophys., 22, 4103-4122, 2004, SRef-ID: 1432-0576/ag/2004-22-4103.

Pinnock, M., Rodger, A. S., and Berkey, F. T.: High-latitude F region electron concentration measurements near noon: A case study, J. Geophys. Res., 100, 7723-7729, 1995.

Pinnock, M., Rodger, A. S., Baker, K. B., Lu, G., and Hairston, M.: Conjugate observations of the day-side reconnection electric field: A GEM boundary layer campaign, Ann. Geophys., 17, 443-454, 1999,

SRef-ID: 1432-0576/ag/1999-17-443.

Pinnock, M., Chisham, G., Coleman, I. J., Freeman, M. P., Hairston, M., and Villain, J.-P.: The location and rate of dayside reconnection during an interval of southward interplanetary magnetic field, Ann. Geophys., 21, 1467-1482, 2003,

SRef-ID: 1432-0576/ag/2003-21-1467.

Siscoe, G. L., and Huang, T. S.: Polar cap inflation and deflation, J. Geophys. Res., 90, 543-547, 1985.

Sotirelis, T., and Newell, P. T.: Boundary-oriented electron precipitation model, J. Geophys. Res., 105, 18655-18673, 2000.

Villain, J.-P., André, R., Pinnock, M., Greenwald, R. A., and Hanuise, C.: A statistical study of the Doppler spectral width of high-latitude ionospheric F-region echoes recorded with SuperDARN coherent HF radars, Ann. Geophys., 20, 1769-1781, 2002 ,

SRef-ID: 1432-0576/ag/2002-20-1769. 